
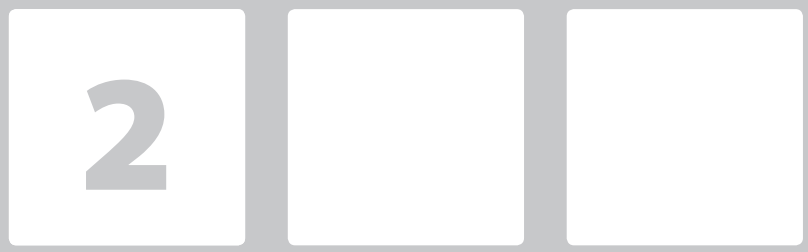

\title{
ANÁLISE DE FATORES INFLUENTES NA RELAÇÃO ENTRE CONTRIBUIÇÕES E BENEFÍCIOS PREVIDENCIÁRIOS
}

\section{Analysis of Influent Factors in the Relationship Between Contributions and Benefits of Social Security}

\section{Luciano Henrique Fialho Botelho}

Doutorando em Administração. Universidade Federal de Viçosa.

Viçosa, MG. Brasil.e-mail: luciano.botelho@hotmail.com

\section{Luiz Antônio Abrantes}

Doutor em Administração. Professor Associado. Universidade Federal de Viçosa.Viçosa, MG. Brasil.e-mail:abrantes.ufv@gmail.com

\section{Marco Aurélio Marques Ferreira}

Pós-Doutorado em Administração Pública. Professor Associado.

Universidade Federal de Viçosa. Viçosa, MG. Brasil.

e-mail:marcoufv1@gmail.com

\section{Thiago de Melo Teixeira da Costa}

Doutor em Economia. Professor Associado. Universidade Federal de

Viçosa.Viçosa, MG. Brasil.e-mail: costatmt@gmail.com

\section{RESUMO}

Este estudo procurou identificar fatores que podem corroborar com as diferenças entre as arrecadações e despesas previdenciárias (RGPS) no que tange aos municípios de Minas Gerais. Na revisão de literatura, discutiu-se as clientelas previdenciárias, a influência dos cenários trabalhistas e demográficos e socioeconômicos na previdência social, o debate sobre o déficit previdenciário e a conexão entre a previdência social, as finanças públicas e o Estado de bem-estar social. Quanto a metodologia, foi utilizada a Análise Exploratória de Dados, Análise Fatorial, e o Teste de Independência de Qui-Quadrado, visando associar entre os fatores encontrados e o Indicador de Resultado Previdenciário Primário (IRPP) criado. Os resultados demonstraram a conexão do IRPP às condições socioeconômicas municipais, confirmando a hipótese testada. Ademais, verificou-se relação entre aspectos de localidade populacional, demográficos, trabalhistas e de desenvolvimento humano com o mesmo indicador. Concluiu-se os desequilíbrios financeiros no RGPS podem ser retratados por cenários socioeconômicos negativos.

Palavras-chave: Previdência Social; Finanças Previdenciárias; Demografia e Mercado de Trabalho; Desenvolvimento Socioeconômico, Minas Gerais.

\section{ABSTRACT}

This study sought to identify factors that can corroborate with the differences between collections and social security expenditures (RGPS) in the municipalities of Minas Gerais. In the literature review, we discussed social security clienteles, the influence of labor and demographic and socioeconomic scenarios on social security, the debate on the social security deficit and the connection between social security, public finances and the welfare state . Regarding the methodology, we used the Exploratory Data Analysis, Factor Analysis, and the Qui-Square Independence Test, aiming to associate between the factors found and the Primary Social Security Result Index (IRPP) created. The results demonstrated the connection of the IRPP to the municipal socioeconomic conditions, confirming the hypothesis tested. In addition, there was a relationship between population, demographic, labor and human development aspects with the same indicator. It was concluded that financial imbalances in the RGPS can be portrayed by negative socioeconomic scenarios.

Keywords: Social Security; Social Security Finances; Demography and Labor Market; Socioeconomic Development, Minas Gerais. 


\section{INTRODUÇÃO}

A seguridade social, nos termos do artigo 194 da Constituição Federal de 1988 (CF/88) compreende um conjunto integrado de ações de iniciativa dos poderes públicos e da sociedade, destinadas a assegurar os direitos relativos à saúde, à previdência e à assistência social. Conforme previsto no texto constitucional, a saúde é direito de todos e dever do Estado, sendo garantida mediante políticas sociais e econômicas com acesso universal e igualitário. Nos mesmos moldes, a assistência social será prestada a quem dela necessitar, independentemente de contribuição à seguridade social. A previdência social, por sua vez, será organizada sob a forma de regime geral, de caráter contributivo e de filiação obrigatória.

No caso da previdência, a Lei Eloy Chaves é considerada o seu marco inicial no Brasil (CUNHA, 2013). A partir do Decreto $N^{\circ} 1$ lei 4.682/1923, criou-se, em cada uma das empresas de estradas de ferro existentes no país, uma caixa de aposentadoria e pensão para os respectivos empregados. Desse modo, o sistema previdenciário tem seu valor quando os indivíduos se encontram impossibilitados de obter renda para a sua sobrevivência, seja devido à idade, doença ou incapacidade para o trabalho, podendo recorrer aos recursos do sistema previdenciário, desde que seus pressupostos legais sejam atendidos (BARR; DIAMOND, 2010).

No Brasil existem dois sistemas de previdência social. Tem-se o Regime Geral de Previdência Social (RGPS) que é responsável pelas contribuições e benefícios oriundos da iniciativa privada ou de entes públicos que não possuem regime próprio e o Regime Próprio de Previdência dos Servidos (RPPS), que pode ser instituído pelos Estados, Municípios e pela União, para o atendimento dos servidores públicos de cada ente. O sistema previdenciário público brasileiro, em regra geral, funciona a partir da distribuição intergeracional ou de repartição simples, no qual a geração atual de contribuintes é responsável pelo financiamento da população contemporânea de beneficiários, não existindo um sistema individual de capitalização dos recursos. Assim, não há uma relação direta em a arrecadação e as despesas da previdência social, fazendo com que flutuações no âmbito exter- no a essa política pública influenciem no equilíbrio financeiro da previdência social (RESENDE, 2001).

Para Afonso (2016) e Matias-Pereira (2010) a idade média da população é um dos fatores que podem influenciar no equilíbrio financeiro da previdência, uma vez que quando a base de contribuintes caí, devido ao envelhecimento da população e/ou a diminuição das taxas de natalidade, pode se resultar em falta de recursos para o pagamento dos aposentados e pensionistas. A informalidade no trabalho também se constitui como um fator que dificulta as finanças previdenciárias, segundo Rocha e Macário (2015) cerca de $46 \%$ da população economicamente ativa (PEA) não contribui para a previdência social.

Outros fatores também são destacados como influentes em um possível resultado financeiro negativo do RGPS brasileiro, a exemplo da previdência rural cujos trabalhadores, no grupo dos segurados especiais, possuem o mesmo benefício dos contribuintes urbanos e têm condições especiais de recolhimento, além de possibilidade de aposentadoria com menor idade ou tempo de contribuição (NERY, 2015; RESENDE, 2001). Ainda, a concentração de pobreza também pode afetar os recursos previdenciários, diante do papel assistencial que a previdência exerce (TAFNER, BOTELHO, ERBISTI, 2015; GIAMBIAGI et al, 2004). O cenário econômico também é um determinando da estabilidade financeira da previdência social. Em períodos de recessão econômica, quando ocorrem aumentos nos números de desempregados, a previdência deixa de arrecadar, diante da redução no número de trabalhadores formais contribuintes para o RGPS, por exemplo (NERY, 2015; DIEESE; ANFIP, 2017).

O panorama da previdência social se apresenta complexo e tem sido alvo de muitos debates diante dos elevados déficits colocadas por diversos autores e, principalmente, pelo Governos Federal. No Brasil, o Ministério da Fazenda apresentou apenas para o RGPS um déficit de 147 bilhões de reais em 2016, sendo que em 2017 o valor estimado passará para 183 bilhões de reais negativos (MARTELLO, 2016). Diversos são os estudos que tratam desse tema, a exemplo de Giambiagi e Além (2016), apontando que a $\mathrm{CF} / 88$ foi responsável pela expansão da previdência social sem criar mecanismos arrecadató- 
rios suficientes para a manutenção do sistema. Em posição antagónica, Gentil (2006, 2017), Salvador (2017) e Ibrahim (2015) consideram a previdência superavitária, dentro do contexto de seguridade social, indicando desvios de recursos da seguridade social para o pagamento de juros da dívida pública, além do problema da falta de transparência com os dados previdenciários.

As finanças previdenciárias também são debatidas no âmbito internacional. No caso dos Estados Unidos da América (EUA) são comuns estudos sobre a troca de um sistema intergeracional da previdência social para um sistema misto, com poupanças individuais, diante dos cenários demográficos, conforme os estudos de Feldstein (2005) e Burkhauser et al (2009). Além disso, Polivka e Luo (2015) debatem sobre as previdências públicas e privadas nos EUA em um âmbito neoliberal e Sass (2015) retrata a relação entre a previdência social e a pobreza entre os idosos. Para a América Latina, Kritzer (2002) também analisou mudanças em sistemas de capitação de recursos em diversos países e Busquets (2012) observou as reformas previdenciárias na região.

Nesse escopo das discussões sobre o equilíbrio financeiro, tendo por base a relação entre arrecadações e pagamentos de benefícios no sistema previdenciário do RGPS, uma questão é levantada: Quais os fatores ocasionam as diferenças entre arrecadações e benefícios previdenciários? Parte-se da hipótese que municípios com melhor situação de desenvolvimento socioeconômico possuem maior equilíbrio entre arrecadações e pagamentos de benefícios no sistema previdenciário do RGPS.

Este estudo tem como objetivo principal analisar e avaliar o resultado primário de arrecadação e pagamento de benefícios do RGPS nos municípios beneficiários do estado de Minas Gerais. Especificamente, pretendeu-se: a) identificar os níveis de arrecadações e benefícios concedidos por mesorregião em Minas Gerais; b) avaliar o comportamento das variáveis de saúde, educação, renda e trabalho, pobreza, demografia e população a partir da estratificação dos municípios em relação ao resultado primário previdenciário; c) identificar os fatores que explicam as situações municipais e avaliar a dependência do resultado primário previdenciário por município em relação aos fatores encontrados.
A relevância deste estudo, considerando a situação financeira do RGPS por município, se justifica pela abertura de espaço para discussão e estabelecimento de variáveis que interferem no equilíbrio financeiro da previdência social, uma vez que o estudo nacional homogeneíza as observações, a exemplo de Nery (2015) e Silva, Costa e Dias (2014). A escolha pelo estado de Minas Gerais se deu devido a marcante desigualdade intermunicipais e inter-regionais e por esse cenário retratar a situação nacional. Em 2013, o índice da Federação das Indústrias do Rio de Janeiro (FIRJAN) de desenvolvimento municipal, que analisa emprego, renda, educação e saúde, apontou que $10,4 \%$ dos municípios mineiros com desenvolvimento municipal crítico, além de evidenciar a concentração dos municípios mais desenvolvidos no sul do estado, em contrapartida com as cidades do norte mineiro (FIRJAN, 2013).

\section{REVISÃO DE LITERATURA}

\subsection{A Previdência Social e a sua Clientela no Brasil}

A previdência social, como uma política social incluída na seguridade social pelo Art. 201 da CF/88, tem como foco o acolhimento econômico dos indivíduos que perderam a sua condição laborativa.

$\mathrm{O}$ estudo sobre a previdência social no Brasil tem um destaque na $\mathrm{CF} / 88$, sendo naquele momento definida as suas formas de custeio, confirmado o sistema de repartição e ampliada a sua atuação. Nesse sentido, as políticas previdenciárias são caracterizadas como amplas e democráticas, diante dos vários públicos que podem ser atendidos pelos esforços do Estado nessa área, principalmente a partir da integralidade de benefícios da clientela rural com a CF/88 (IBRAHIM, 2015).

Alguns trabalhos sobre a previdência social fazem a divisão entre a clientela urbana e rural para essa política, a exemplo de Nery (2015). Outros abordam as diferenças entre as regras para a concessão da aposentadoria entre ambas as clientelas, casos de Bitencourt et al (2011) e Tanaka (2016). Com relação ao público rural previdenciário, ademais, a Lei de Benefícios da Previdência Social (8.213/91) 
apresentou: o segurado especial, o empregado rural e o contribuinte individual (BRASIL, 1991). O empregado rural e o contribuinte individual possuem regras semelhantes às dos segurados urbanos, com exceção da redução em 5 anos no tempo de contribuição. Para fins deste artigo, torna-se relevante abordar a figura do segurado especial, que enquadra pequenos produtores da agricultura familiar contribuintes sobre uma alíquota de 2,1\% da sua comercialização, quando existir (TANAKA, 2016).

Tais diferenças legais para a clientela previdenciária rural são discutidas na literatura como prejudiciais ao equilíbrio entre as arrecadações e os benefícios do RGPS, como retrata Nery (2015), tornando-se, portanto, relevante para os fins deste estudo. Quando se observa as despesas e receitas da previdência rural é verificado um desequilíbrio, entretanto, a legislação estabelece os pressupostos para a manutenção da previdência rural, principalmente devido à enorme influência dessa política no que concerne ao âmbito social, em evidência na redução da pobreza (CONTAG, 2016; BELTRÃO; OLIVEIRA; PINHEIRO, 2000; DELGADO, 2015).

\subsection{Outros Fatores Associados à Previdência Social}

Além da questão das clientelas, outras situações são observadas pela literatura em relação ao equilíbrio financeiro da previdência social no Brasil. Aspectos demográficos são um destaque principalmente no que concerne ao envelhecimento da população, conforme visão de Resende (2001). Desse modo, Matias-Pereira (2010) apontou a existência de 100 crianças para cada 24 idosos em 2008 e projeta para 2050 a relação de 100 crianças para cada 173 idosos. Ainda, segundo o referido autor, utilizando dados do Instituto Brasileiro de Geografia e Estatística (IBGE), a esperança de vida dos brasileiros passou de 67 anos em 1991 para 72,57 em 2007, sendo que em 2015 já havia chegado a 75,2 anos.

Todas essas mudanças afetam a previdência social, por um lado se tem um aumento da população em idade ativa, que pode contribuir para a previdência social, e por outro, a médio e longo prazo, projeta-se uma grande faixa da população dependente dos recursos da previdência social (MATIAS-PEREIRA,
2010). A despeito, as dificuldades previdenciárias envolvendo aspectos demográficos não são exclusividade brasileira, Esping-Anderson (1995) já relatava que as tendências demográficas também afetam as finanças da seguridade social.

No que se refere as dificuldades que a evolução demográfica pode trazer a previdência social, Silva, Costa e Dias (2014) argumentam que o regime de repartição simples, que é característico do RGPS, pode proporcionar o aumento dos gastos sem respaldo nas receitas previdenciárias, diante do envelhecimento da população, nesse sentido, o Estado deve agir na busca do equilíbrio financeiro da previdência social.

A evolução da população em idade economicamente ativa, conforme traz Matias Pereira (2010), poderia resultar em ganhos para a previdência social, uma vez que a previdência é custeada, em grande medida, pelos trabalhadores com carteira assinada. Desse modo, o cenário trabalhista é fundamental para a manutenção da saúde financeira da previdência social. Entretanto, alguns fatores interferem nesse cenário, a exemplo do desemprego, que reduz a contribuição à previdência social e o alto grau do trabalhismo informal vigente no Brasil, com o qual grande parte da população não contribui e não têm seus direitos a proteção social pela previdência social (SILVA; COSTA; DIAS, 2014; ROCHA; MACÁRIO, 2015).

O número de financiadores do RGPS em 2013 era cerca de 53 milhões de contribuintes, número considerado baixo quando se observa um país que possuiu 103 milhões de habitantes classificados como economicamente ativos pelo IBGE (PREVIDÊNCIA SOCIAL, 2015). Ademais, Resende (2001) discorre que em sistemas de repartição, como no caso brasileiro, não existe relação direta entre as contribuições e os benefícios fazendo com que as flutuações econômicas, que corroboram com cenários trabalhistas mais difíceis, afetem gravemente as finanças previdenciárias. Uma das principais bases para a manutenção da previdência social é o crescimento econômico, sendo que seus principais tributos de financiamento são incidentes sobre o lucro, faturamento e folha de salários das empresas (DIEESE; ANFIP, 2017).

Os recursos inseridos pela previdência social nos variados contextos, com destaque no âmbito municipal e em regiões rurais, são relevantes no que 
concerne ao desenvolvimento econômico e ao combate à pobreza. Desse modo, Reis, Silveira e Braga (2013) colocam a previdência social como uma das principais políticas públicas no escopo social, contribuindo para os esforços de bem-estar social.

A previdência social corrobora para o estabelecimento de uma melhor qualidade de vida familiar e para o fortalecimento da economia das cidades, principalmente as de pequeno porte, diante do acréscimo na renda familiar e do incentivo ao consumo de bens e serviços (SILVA; COSTA; DIAS, 2014). A despeito, Silva et al (2013) coloca que o sistema previdenciário do RGPS favorece a erradicação da pobreza extrema no Brasil, com a transferência de renda para famílias em situação de exclusão social.

Essa atuação extremamente relevante para os pequenos municípios, quando são vislumbradas como benefícios assistenciais, apresentados pela Lei Orgânica da Assistência Social (LOAS), no entanto, na visão de Giambiagi et al (2004), contribuem para as dificuldades financeiras da previdência social. Para o referido autor, mesmo não sendo gastos diretos da previdência social, pois são programas de assistência social, fazem com que os indivíduos não procurem contribuir para a previdência social, uma vez que se contribuírem provavelmente no futuro receberão os mesmos que recursos que já recebem sem contribuição, de forma assistencial.

\subsection{Discussões sobre o Déficit Previdenciário}

A seguridade social, nos termos dos artigos 11 e 27 da Lei 8.212/91, será custeada pelas receitas da união, contribuições sociais e por demais receitas. Nesse escopo, as contribuições sociais resultantes de contribuições diretas à previdência social, como o caso das contribuições sobre a folha de pagamento, ou de outras contribuições como a Contribuição para a Seguridade Social (COFINS) e a Contribuição Social sobre o Lucro Líquido (CSLL), compõe as principais receitas da seguridade social. As contribuições, sem vinculação específica, como o caso da CSLL, podem ser aplicadas na previdência, na saúde ou na assistência social.

Nesse contexto que ocorrem as principais discussões sobre o resultado financeiro da previdência social. Observando apenas as receitas destinadas à previdência social, caso da contribuição sobre a folha de pagamentos e contribuições das empresas, e as despesas previdenciárias, verifica-se um déficit previdenciário no RGPS, como destacam Giambiagi e Além (2016), Resende (2001), Tafner, Botelho e Erbisti (2015) e Nery (2015).

Ao se considerar o orçamento integral, por outro lado, com os outros recursos da seguridade social, conforme determina $\$ 2^{\circ}$ Art. 195 da CF/88, a exemplo do uso da CSLL e do COFINS, apura-se um superávit da seguridade social e recursos para a manutenção da previdência social, pela visão de Gentil (2006, 2017), Serau Júnior (2012), Salvador (2017) e Rocha e Macário (2015). Assim, existem duas versões: a visão de déficit da previdência no RPGS e da necessidade de reformas e a colocação da seguridade social superavitária, que corrobora com a previdência social superavitária, apoia na $\mathrm{CF} / 88$. A colocação da previdência social deficitária, ademais, se apoia no entendimento que o RGPS deve possuir menor impacto nas contas públicas, principalmente observando o longo prazo e a necessidade dos recursos da seguridade social também para a assistência social e a saúde pública, que são prejudicadas com o subfinanciamento no Brasil, situação apontada por Yazbek (2015) e Almeida-Filho, Paim e Silva (2014), respectivamente. Contudo, tais observações, conforme apontam Ibrahim (2015), Gentil (2017) e Salvador (2017), não demonstram o efeito de políticas fiscais que retiram elevados montantes do orçamento da seguridade social, caso da Desvinculação de Receitas da União (DRU) e das desonerações tributárias, valores que seriam de grande validade.

\subsection{Finanças Públicas e a Previdência Social no contexto do Estado de Bem-Estar Social}

A previdência social, pertencente à seguridade social, pode ser vista como uma política de proteção social alinhada ao Estado de Bem-Estar social, sendo esse, segundo Esping-Andersen (1990), um Estado com maior ideal social, alicerçado no fornecimento de garantias básicas aos cidadãos, seja em formato de saúde, alimentação, moradia, educação ou previdência. Nesse âmbito, os estudos sobre as finanças 
públicas, que se ocupam em analisar "a obtenção, distribuição, utilização e controle dos recursos financeiros do Estado", como argumenta Matias-Pereira (2010, p.113), também perpassa pela observação da evolução e crise do Estado de Bem-Estar Social.

O século XX foi marcado por grandes movimentos que reconfiguraram as visões sobre as atividades que o Estado deveria assumir em relação aos atendimentos a população e a sua preocupação com as políticas sociais e as desigualdades sociais. Desse modo, existiram vários episódios que culminaram com a evolução das políticas para um Estado de Bem-Estar Social, destaca-se a crise de 1929, a grande depressão da década de 1930 e as duas guerras mundiais (RESENDE, 2001; HOBSBAWM, 1995). A teoria do "Efeito-Translação" de Peacock e Wiseman vem discutir como ocorreu o aumento dos tributos para a manutenção do Estado de Bem-Estar Social com a evolução das despesas públicas, durante o século XX. Segundo essa teoria, os problemas sociais e inflacionários vislumbrados proporcionaram a oportunidade de aumentos na carga tributária e até mesmo o crescimento na emissão de papel-moeda, o que corroborou com a elevação da dimensão estatal (RESENDE, 2001).

De acordo com Giambiagi e Além (2016), com a ampliação de suas bases, o Estado assumiu a missão de controlar as políticas fiscais em três dimensões. Através das políticas alocativas, o Estado passou a direcionar os recursos como forma de atender as demandas da sociedade e do mercado; pelas práticas distributivas, o Estado teve como ênfase a redução das desigualdades sociais; e a com as políticas estabilizadoras, se propôs a estabilizar a econômica principalmente a partir da manutenção da demanda agregada e do controle do desemprego, sendo que o estabelecimento do pleno emprego é uma das principais vertentes do Estado de Bem-Estar Social (ESPING-ANDERSON, 1990; GIAMBIAGI; ALÉM , 2016).

Entretanto, Matias-Pereira (2010, p. 78), ressalta que a crescente intervenção governamental na economia vislumbrada a partir da década de 1930 começou a se deparar com novas questões que resultam no enfraquecimento do Estado de Bem-Estar Social, principalmente a partir de meados da década de 1980 . Nesse período, "questões como aumento populacional, elevação da longevidade média, inovações tecnológicas e o ressurgimento do desemprego em massa foram decisivas para inviabilizar os sistemas de previdência social, e, dessa forma, conquistas históricas".

Surgiram nesse período as discussões sobre a incapacidade do Estado em atender todas as demandas da sociedade que geravam "custos econômicos insuportáveis", culminado com crises fiscais (MATIAS-PEREIRA, 2010, p. 80). Davi et al (2010) argumenta que as crises fiscais na verdade consistem no crescimento das ideologias de Estado Mínimo e da ascensão neoliberal. Nesse espoco, evidencia-se a preocupação com as políticas de proteção, uma vez que se tem espaço para a transferência das atividades públicas de seguridade social para o mercado (DAVI et al, 2010). Foi visível, principalmente na Europa e nos Estados Unidos da América, a partir da década de 1980, grandes reformas fiscais que trouxeram frouxidões ao controle do mercado pelo Estado e privatizações, medidas que corroboraram com o aumento das desigualdades sociais (MATIAS-PEREIRA, 2010; POLIVKA; LUO, 2015).

No contexto atual, Matias-Pereira (2010) ressalta a manutenção do viés de redução das despesas públicas destinada a proteção social, que podem comprometer a previdência social. Por fim, Resende (2001) afirma que a principal questão que deve estar envolta das dimensões do Estado são as necessidades que o país possui, enquanto mais complexos foram os problemas sociais vigentes, maior deve ser a atuação do Estado.

\section{METODOLOGIA}

Este estudo se configura como de natureza quantitativa e de objetivo descritivo, o qual procura, segundo Gil (1999), expor as características e fatores envolvimentos em determinados fenômenos. Ademais, para a análise de dados foi utilizado o programa Statistical Package for the Social Sciences (IBM-SPSS, Versão 20). 


\subsection{Coleta de Dados e Descrição das Variáveis}

Para este estudo foram coletados dados secundários através do portal Atlas do Desenvolvimento Humano no Brasil, que tem como referência o Censo de 2010, realizado pelo Instituto Brasileiro de Geografia e Estatística (IBGE). Foram utilizados indicadores de desenvolvimento socioeconômico (IDHM, IDHM Renda, IDHM Longevidade, Percentual da População Vulnerável a Pobreza e Taxa de Mortalidade Infantil), dados demográficos (Taxa de Envelhecimento), variáveis trabalhistas (Taxa de Atividade e Percentual da Renda Proveniente do Trabalho), informações sobre localidade populacional (População Rural e População Urbana) e características de escolaridade (IDHM Educação e Expectativa de Anos de Estudo), variáveis de desenvolvimento humano.

Utilizou-se também de dados referentes à Previdência Social no que concerne as estatísticas municipais, essas informações constam de valores arrecadados por munícipios e os recursos dispendidos pelo RGPS nessas localidades. Em relação às arrecadações, os montantes correspondem as receitas incluídas nas Guias da Previdência Social (GPS), no período de janeiro a dezembro do ano de 2010. As desonerações da folha de pagamento que passaram a ocorrer em 2011, não afetam o estudo. Os benefícios consistiram nos pagamentos realizados pelo RPGS sobre direitos a aposentadorias e pensões, incluindo também os benefícios de invalidez, ou seja, todos aqueles que são de responsabilidade do RPGS e consequentemente do Instituto Nacional do Seguro Social (INSS), sua autarquia gestora. O Indicador Firjan de Desenvolvimento Municipal (IFDM), criado pela Federação das Indústrias do Rio de Janeiro (FIRJAN), do ano de 2010, também foi utilizado como variável para este estudo.

Com relação aos dados da previdência social, criou-se uma variável Indicador de Resultado Primário Previdenciário (IRPP), sendo resultante da divisão dos valores arrecadados pelas despesas com benefícios pagos em cada município de Minas Gerais. Nesse caso, quanto menor o IRPP pior é o resultado primário do RGPS no município, uma vez que esse resultado representa uma maior diferença entre os valores pagos em benefícios e os montantes arrecadados. Assim, foram considerados deficitários os municípios que apresentam IRPP menor que 1 . Ressalta-se que dos 853 municípios do estado de Minas Gerais, 320 foram excluídos da amostra, diante da ausência de dados nas planilhas disponibilizadas pela previdência social.

Destaca-se que as variáveis descritas foram escolhidas para este estudo a partir das observações feitas na revisão de literatura, portanto, possuem conexão teórica direta com o objeto analisado.

\subsection{Operacionalização dos Dados}

Com relação aos procedimentos deste estudo, inicialmente foi efetuada uma análise exploratória dos dados (AED) para em seguida ser aplicada a análise fatorial nas variáveis selecionadas e, por fim, foi realizado o teste de independência de qui-quadrado visando responder a hipótese do trabalho.

\subsubsection{Análise Exploratória de Dados}

Com a análise exploratória de dados (AED) se tem a possibilidade de entender o comportamento dos dados, antes de utiliza-los ou adapta-los, nesse sentido, é importante na descrição das características dos dados e na análise numérica do comportamento dos mesmos. A partir da análise exploratória dos dados se tem a possibilidade de extrair as informações e gerar novas hipóteses, antes da aplicação de qualquer técnica estatística (BATANERO; ESTEPA; GODINO, 1991).

Além da análise por variável, para a AED, presente neste estudo, foram estabelecidas categorias para a variável IRPP, como forma de se realizar uma análise mais aprofundada. Nesse sentido, as categorias foram criadas a partir da média e do desvio padrão dos IRPPs de cada município. Os municípios com IRPPs menores ou iguais a 0,281 (média) foram classificados como em situação "crítica", os resultados entre 0,282 e 0,436 (média mais meio desvio padrão) 
correspondem a categoria "ruim" e os IRPPs maiores que 0,436 foram nomeados como de situação "regular/boa". Para o objetivo específico que compreende a análise do nível de arrecadação e benefícios por Mesorregião de Minas Gerais, também na AED é demonstrada a situação do IRPP para cada Mesorregião desse ente federativo.

\subsubsection{Análise Fatorial}

A análise fatorial objetiva, conforme destaca Pestana e Gageiro (2008), a correlação de variáveis, procurando simplificar os dados em fatores. Com a análise fatorial se tem a possibilidade de verificar se certas variáveis estão medindo os mesmos conceitos, além disso, a análise fatorial permite realizar a estimação da importância dos fatores (PESTANA; GAGEIRO, 2008). Hair et al (2005) relata que esse método facilita a interpretação e a compreensão das variáveis uma vez que torna possível verificar o poder de explicação de determinada variável em relação ao grupo de variáveis estudadas.

Com relação aos procedimentos demandados para a realização da análise fatorial, Figueiredo e Silva (2010) relata que deve se verificar a adequação do banco de dados (uso de variáveis contínuas, mínimo de 100 casos, análise de correlações superiores a 0,3 e teste de medida de adequação da amostragem (KMO) superior a 0,6 com nível de significância menor que 0,05). Ainda, segundo Figueiredo e Silva (2010) a segunda etapa consiste em estabelecer a técnica de extração dos fatores e, por último, o investigador deve determinar o número de fatores que serão extraídos, o melhor número de fatores para representar as variáveis.

\subsubsection{Teste de Normalidade e Teste de Independência de Qui-Quadrado}

A partir do teste de Kolmogorov-Smirnov foi analisada a normalidade da variável IRPP, esse teste segundo Pestana e Gageiro (2008) analisa a aderência da distribuição a normalidade. O teste de Kolmogorov-Smirnov apresentou nível de significância igual a zero, o que permite a rejeição da hipótese $\mathrm{H} 0$, a qual afirma que a variável indicador de resultado previdenciário primário (IRPP) possui distribuição normal.

$O$ resultado anterior possibilitou a utilização do teste de independência do qui-quadrado. $\mathrm{O}$ teste de independência do qui-quadrado consiste em um método não paramétrico que tem como objetivo, conforme destaca Maciel et al (2015), identificar a independência de duas variáveis de qualquer tipo. Tem-se na sua hipótese nula que as variáveis são independentes e na hipótese alternativa que as variáveis são dependentes. Para este estudo, o teste de qui-quadrado foi ajustado a partir da correção de Monte Carlo, responsável por substituir o qui-quadrado caso se tenha frequência esperada menor que 5. Foi adicionado também ao qui-quadrado o teste de Mantel-Haenszel para confirmar a associação linear de variáveis, uma vez que as variáveis são medidas escalares intervalares (MANTEL; HAENSZEL, 1959; MACIEL et al, 2015).

\section{RESULTADOS E DISCUSSÕES}

\subsection{Avaliação dos dados e dos níveis de arrecadações e benefícios previdenciários nas mesorregiões mineiras}

De todos os municípios analisados, apenas oito apresentaram superávit primário, ou seja, Indicador de Resultado Primário Previdenciário (IRPP) maior ou igual a 1, os restantes, além do déficit primário constatado, apresentaram variações consideráveis quando se avalia a magnitude dos valores. Observando a Tabela 1, percebe-se grande distanciamento entre o valor mínimo e máximo da variável IRPP, indicando a dispersão elevada dos valores. A média próxima ao valor mínimo, demonstra a concentração de baixos indicadores. $\mathrm{O}$ desvio padrão apresentou a variação em torno da média relativamente alta e a curtose bem superior a zero sugerindo uma distribuição alta, afunilada e superior à normal. 
Tabela 1 Análise exploratória de dados.

\begin{tabular}{|c|c|c|c|c|c|c|}
\hline Variáveis & Mínimo & Máximo & Média & $\begin{array}{l}\text { Desvio } \\
\text { Padrão }\end{array}$ & Assimetria & Curtose \\
\hline IRPP & ,002 & 4,268 & ,286 & ,309 & 6,490 & 67,687 \\
\hline FDM & ,395 &, 848 &, 639 &, 088 &,- 100 &,- 465 \\
\hline Taxa de atividade & 31,100 & 76,200 & 56,117 & 6,038 &,- 399 &, 640 \\
\hline Esperança de vida ao nascer & 68,390 & 78,100 & 74,604 & 1,719 &,- 254 &,- 311 \\
\hline População Urbana & ,209 & 1,000 & ,711 & , 180 &,- 426 &,- 683 \\
\hline Mortalidade infantil & 10,500 & 27,800 & 16,077 & 2,773 &, 501 &, 252 \\
\hline IDHM &, 529 & 813 &, 675 &, 047 &,- 033 &,- 187 \\
\hline IDHM Renda &, 502 &, 864 &, 659 &, 053 &,- 037 &,- 096 \\
\hline IDHM Longevidade &, 723 &, 885 &, 827 &, 028 &,- 258 &,- 306 \\
\hline IDHM Educação &, 339 &, 744 &, 566 &, 066 &, 080 & ,063 \\
\hline Expectativa de anos de estudo & 6,610 & 11,040 & 9,124 &, 726 &,- 355 &, 265 \\
\hline Renda per capita & 181,770 & 1731,840 & 512,093 & 173,409 & 1,315 & 5,596 \\
\hline$\%$ da renda originada trabalho & 37,780 & 89,950 & 69,396 & 8,202 &,- 339 &, 039 \\
\hline$\%$ de extremamente pobres &, 000 & 33,880 & 5,667 & 5,840 & 1,567 & 2,356 \\
\hline \% de vulneráveis à pobreza & 10,770 & 77,310 & 38,762 & 15,131 &, 294 &,- 946 \\
\hline
\end{tabular}

Fonte: Dados da pesquisa.

Tabela 2 Análise do IRPP por Mesorregião Mineira

\begin{tabular}{|c|c|c|c|c|}
\hline Mesorregiões & $\begin{array}{c}\text { Arrecadação } \\
\text { (Milhões) }\end{array}$ & $\begin{array}{l}\text { Benefícios } \\
\text { (Milhões) }\end{array}$ & IRPP & № de Municípios \\
\hline Campos das Vertentes & 360 & 937 & 0,384 & 17 \\
\hline Central de Minas & 404 & 1.018 & 0,397 & 16 \\
\hline Jequitinhonha & 291 & 872 & 0,334 & 33 \\
\hline Metropolitana & 9.914 & 7.552 & 1,313 & 68 \\
\hline Noroeste de Minas & 277 & 685 & 0,404 & 14 \\
\hline Norte de Minas & 992 & 2.779 & 0,357 & 50 \\
\hline Oeste de Minas & 156 & 548 & 0,284 & 27 \\
\hline Sul/Sudoeste de Minas & 834 & 2.569 & 0,325 & 103 \\
\hline Triângulo Mineiro/Alto Paranaíba & 878 & 2.243 & 0,392 & 48 \\
\hline Vale do Mucuri & 866 & 1.076 & 0,805 & 13 \\
\hline Vale do Rio Doce & 2.091 & 2.719 & 0,769 & 65 \\
\hline Zona da Mata & 1.071 & 2.920 & 0,367 & 79 \\
\hline TOTAL & 18.135 & 25.916 & 0,286 & 533 \\
\hline
\end{tabular}

Fonte: Dados da pesquisa. 
Tabela 3 Municípios Superavitários por Mesorregião

\begin{tabular}{c|c}
\hline Municípios Superavitários & Mesorregiões \\
\hline Belo Horizonte & Metropolitana \\
\hline Belo Oriente & Vale do Rio Doce \\
\hline Carvalhos & Sul/Sudoeste de Minas \\
\hline Confins & Metropolitana \\
\hline Nova Serrana & Oeste de Minas \\
\hline Rio Acima & Metropolitana \\
\hline São Thiago & Campos das Vertentes \\
\hline Uberlândia & $\begin{array}{c}\text { Triangulo Mineiro e } \\
\text { Alto Paranaíba }\end{array}$ \\
\hline
\end{tabular}

Fonte: Dados da pesquisa.

Alguns desses mesmos comportamentos puderam ser observados em outras variáveis analisadas, que apresentaram grandes variações entre os valores mínimos e máximos, indicando a heterogeneidade e a desigualdade entre essas variáveis nos municípios avaliados. A relação entre as médias e os desvios padrões evidenciam, por outro lado, uma pequena dispersão dos dados para a maioria das variáveis, com exceção do percentual da presença populacional de pessoas extremamente pobres.

As medidas de assimetria e curtose demonstram a existência de distribuições próximas a simetria e com curvas próximas a mesocúrticas possuindo valores relativamente baixos, com exceção das variáveis percentual de extremamente pobres e renda per capita. Observa-se assim tendências de distribuições normal em todas as variáveis, com exceção da IRPP.

A análise por mesorregião se tornou importante diante heterogeneidade vislumbrada nos indicadores socioeconômicos em Minas Gerais, que são condizentes com a situação nacional. De acordo com Tabela 2 apenas a mesorregião Metropolitana se apresentou superavitária, com IRPP maior que 1 , sendo que dos oito municípios superavitários, três estão localizados nessa mesorregião, conforme Tabela 3.

Segundo Carvalho e Ribeiro (2015), a mesorregião metropolitana de Minas Gerais apresenta o melhor Índice Relativo de Qualidade de Vida (IRQV) do estado. Corroborando, Cirino e González (2011), relatam que a mesorregião metropolitana é responsável pelos melhores indicadores sociais e econômicos de Minas Gerais. Nesse escopo, é observado a ideia da influência socioeconômica no resultado previdenciário primário, colocada por Giambiagi (2004), Nery (2015), Silva et al (2013) e DIEESE e ANFIP (2017). A previdência social pode assumir relações mais equilibradas entre arrecadações e pagamentos de benefícios nas regiões em que não existe uma forte dependência dos recursos previdenciários para a manutenção local ou em regiões socioeconomicamente mais desenvolvidas.

Com relação a mesorregião que possui situação mais crítica no âmbito do resultado previdenciário primário, a mesorregião Oeste de Minas se destaca, estando essa em situação mais difícil que as mesorregiões Norte de Minas, Jequitinhonha e Vale do Mucuri, colocadas por Carvalho e Ribeiro (2015) e Cirino e González (2011) como aquelas com menor desenvolvimento socioeconômico do estado.

A mesorregião Oeste de Minas apresentou situações intermediárias quando se tratou dos aspectos sociais e econômicos, aportando, porém, somente o município de Nova Serrana superavitário em relação ao IRPP. Esse município possui maior potencial econômico, principalmente devido à presença de fortes indústrias de calçado (SUZIGAN et al, 2005)

\subsection{Comportamento das Variáveis estratificadas pelo Resultado Previdenciário Primário}

Foram criadas categorias por município de acordo com os resultados obtidos na formação do Indicador de Resultado Primário Previdenciário (IRPP). Assim, agrupou-se 350 municípios em estratos considerados como situação em crítica, 96 em situação ruim e apenas 87 em situação regular/boa (Tabela 4). Considerando os municípios classificados nos estratos de situação regular/boa, observa-se que as médias se apresentaram mais elevadas nas variáveis IFDM, IDHM, IDHM Renda, IDHM Educação, IDHM Longevidade, Expectativa de Anos de Estudo, Percentual de Recursos Provenientes do Trabalho, Taxa de Atividade e População Urbana. Observou-se o contrário nas variáveis relacionadas ao percentual da População Vulnerável a Pobreza, ao Percentual da População em Situação de Extrema Pobreza, a Taxa de Mortalidade Infantil e a Taxa de Envelhecimento. 
Tabela 4 Comportamento das variáveis nas categorias do IRPP.

\begin{tabular}{l|c|c|c}
\multicolumn{1}{c|}{ Variáveis } & Crítica & Regular/Boa & Ruim \\
\hline IFDM & 0,623 & 0,686 & 0,658 \\
\hline Expectativa de anos de Estudos & 9,092 & 9,271 & 550,965 \\
\hline Renda per capita & 477,020 & 610,300 & 0,687 \\
\hline IDHM & 0,665 & 0,700 & 0,672 \\
\hline IDHMRenda & 0,650 & 0,686 & 0,831 \\
\hline IDHMLongevidade & 0,822 & 0,840 & 0,581 \\
\hline IDHMEducação & 0,554 & 0,598 & 71,103 \\
\hline Percentual da renda proveniente de rendimentos do trabalho & 67,927 & 73,423 & 36,031 \\
\hline Percentual de vulneráveis à pobreza & 41,393 & 31,192 & 4,562 \\
\hline Percentual de extremamente pobres & 6,516 & 3,473 & 15,604 \\
\hline Taxa de Mortalidade infantil & 16,508 & 14,868 & 8,882 \\
\hline Taxa de envelhecimento & 9,453 & 8,088 & 56,978 \\
\hline Taxa de atividade & 55,123 & 59,166 & 0,774 \\
\hline População Urbano & 0,674 & 0,788 & \\
\hline
\end{tabular}

Fonte: Dados da pesquisa.

Esses resultados corroboram para a observância da influência dos indicadores socioeconômicos no IRPP. Percebe-se, além disso, que a preponderância de uma maior taxa de envelhecimento é observada em municípios classificados como em situação crítica, sendo que em munícipios com situação regular/boa, a taxa de atividade apresentou-se mais elevada. É possível observar ainda a concentração de uma maior população urbana e melhores índices de educação para os municípios com situação mais confortável no IRPP.

As observações são colaboradas pelo estudo de Matias-Pereira (2010) que discorreu sobre a influência demográfica no equilíbrio financeiro da previdência social, no trabalho de Resende (2001) e relatório no DIEESE e ANFIP (2017) que trataram das flutuações econômicas e do mercado de trabalho e seu impacto na arrecadação previdenciária, em Nery (2015) e Resende (2001) que abordaram a questão da concentração de população urbana e nas questões relatadas por Giambiagi (2004) em que a existência da necessidade de maiores atenções assistenciais pelo Estado em determinadas localidades acabam por influenciar a sustentabilidade financeira do RGPS.

\subsection{Observação dos fatores municipais}

A análise fatorial aplicada apresentou significativo ajustamento e nível de significância. Conforme Quadro 1, o ajustamento, medido pelo teste de KMO (Kaiser-Meyer-Olkin), apresentou resultado superior a 0,6, que segundo Figueiredo e Silva (2010) e Hair et al (2005) indicam a qualidade dos dados. O teste de Bartlett's validou a análise fatorial com nível de significância inferior a 0,05 , dessa forma se rejeita a hipótese de não existência de correlação entre os dados (HAIR et al, 2005). 
Quadro 1 teste KMO e teste de Bartlett's

\begin{tabular}{l|l|l}
\hline \multicolumn{2}{l|}{ Teste KMO } & 0,833 \\
\hline \multirow{2}{*}{ Teste de Battlett's } & Approx. Chi-Square & 13320,207 \\
\cline { 2 - 3 } & Df & 91 \\
\cline { 2 - 3 } & Sig. & 0,000 \\
\hline
\end{tabular}

Fonte: Dados da pesquisa.

Pela rotação das variáveis efetuada pelo método Varimax, a análise fatorial resultou em 3 fatores com raiz característica superiores a 1 correspondendo a $78,84 \%$ da variância dos dados, conforme Tabela 5. A análise das correlações das variáveis que correspondem ao constructo apresentou nível de significância igual a zero na matriz de covariância para os três fatores.

Tabela 5 Resultado da formação dos fatores

\begin{tabular}{c|c|c|c}
\hline Fatores & $\begin{array}{c}\text { Raiz de Ca- } \\
\text { racterística }\end{array}$ & $\begin{array}{c}\text { Percentual } \\
\text { de Variância }\end{array}$ & $\begin{array}{c}\text { Variância } \\
\text { Acumulada }\end{array}$ \\
\hline 1 & 8,452 & 60,370 & 60,370 \\
\hline 2 & 1,474 & 10,527 & 70,898 \\
\hline 3 & 1,112 & 7,941 & 78,838 \\
\hline
\end{tabular}

Fonte: Dados da pesquisa.

O fator 1, composto pelas variáveis IDHMRenda, Percentual de Vulneráveis a Pobreza, IDHMLongevidade, Taxa de Mortalidade Infantil, Renda Per Capta, IDHM, Percentual de Extremamente Pobres, IFDM e Percentual de População Urbana, foi nomeado fator Desenvolvimento Socioeconômico e Localização Populacional. O segundo fator, nomeado fator Demografia e Trabalho, foi formado pelas variáveis Taxa de Envelhecimento, Percentual da Renda Proveniente do Trabalho e Taxa de Atividade. Por fim, o terceiro fator corresponde as variáveis IDHMEducação e Expectativa de Anos de Estudo recebeu o nome de Escolaridade. Ressalta-se que as variáveis por fator foram discorridas de acordo com o nível de correlação, sendo que no fator 1 as variáveis Percentual de Vulneráveis a Pobreza, Taxa de Mortalidade Infantil e Percentual de Extremamente Pobres obtiveram correlação negativa, assim como a Taxa de Envelhecimento no fator 2.
Percebeu-se a grande influência do fator desenvolvimento socioeconômico e localidade populacional na descrição das correlações desses municípios, que apresentou variância de 60,37\%, é importante destacar que a variância demonstra o autopoder de explicação dos dados pelos fatores. O fator demografia e trabalho também se demonstrou relevante na descrição sintética das variáveis para os municípios analisados, assim como o fator escolaridade, com variâncias de 10,527\% e 7,941\%, respectivamente.

\subsection{Fatores Influentes nos Resultados Previdenciários}

Testando a independência entre o IRPP e o desenvolvimento socioeconômico e localização populacional, variáveis componentes do fator 1 foi constatado, após aplicação do teste de Qui-Quadrado e Mantel-Haenszel, nível de significância de zero para um intervalo de confiança de 99\%, assim, rejeitou-se a hipótese nula, uma vez que existem evidências estatísticas da relação de dependência entre o fator desenvolvimento socioeconômico e localidade populacional com o resultado previdenciário primário para os municípios de Minas Gerais.

Realizando o mesmo teste para os outros fatores municipais observados neste estudo, Tabela 6, encontrou-se resultados análogos ao anterior para os outros 2 fatores, com intervalo de confiança de 99\%, indicando que aspectos demográficos e de trabalho estão associados ao indicador de resultado primário previdenciário, da mesma forma que a escolaridade.

Nesse escopo, com a existência de evidências estatísticas que comprovam a hipótese proposta, além das outras alternativas testadas, este estudo corrobora com várias das perspectivas vislumbradas na revisão de literatura. No que tange ao fator 1, aquele com maior variância na análise fatorial, evidencia-se a influência do desenvolvimento socioeconômico local na situação positiva de financeiramente do RGPS naquele determinado município. Conforme ressalta Giambiagi et al (2004), a falta de desenvolvimento socioeconômico contribui para a baixa arrecadação nesses locais, que muitas vezes possuem grande número de indivíduos dependentes de recursos do Estado e com baixa possibilidade de contribuição para a previdência. Por outro lado, municípios socioeco- 
nomicamente mais desenvolvidos possuem melhores condições de renda, saúde, educação e emprego, o que facilita a contribuição para a previdência social.

Tabela 6 teste de qui-quadrado e Mantel-Haenszel

\begin{tabular}{l|c}
\hline \multicolumn{1}{c|}{ Variáveis Testadas } & $\begin{array}{c}\text { Sig. do Teste de } \\
\text { qui-quadado e } \\
\text { Mantel-Haenszel }\end{array}$ \\
\hline $\begin{array}{l}\text { Fator } \mathbf{1} \text { (desenvolvimento socioeconômico e } \\
\text { localidade populacional) associação com indi- } \\
\text { cador de resultado primário previdenciário }\end{array}$ & 0,000 \\
\hline $\begin{array}{l}\text { Fator } \mathbf{2} \text { (demografia e trabalho) associa- } \\
\text { ção com indicador de resultado primário } \\
\text { previdenciário }\end{array}$ & 0,002 \\
\hline $\begin{array}{l}\text { Fator } \mathbf{3} \text { (escolaridade) associação com indi- } \\
\text { cador de resultado primário previdenciário }\end{array}$ & 0,003 \\
\hline
\end{tabular}

Fonte: Dados da pesquisa

A literatura traz com frequência a descrição da influência dos recursos aplicados pela previdência social na manutenção e desenvolvimento econômico de pequenos municípios, conforme é colocado por Silva, Costa e Dias (2014) e Silva et al (2013), este estudo apresenta a confirmação da relação oposta, ou seja, o impacto da situação socioeconômica do município no equilíbrio financeiro da previdência social em âmbito local. A existência de um sistema econômico mais forte, que propicie maiores recolhimentos tributários sobre a folha de salários dos trabalhadores favorece o equilíbrio financeiro do RGPS nos municípios (DIEESE; ANFIP, 2017). Pode se considerar, desse modo, que talvez os maiores problemas financeiros do RGPS podem não estar ligados à sua operacionalização, mas ao desequilíbrio socioeconômico local.

Ainda, em relação ao fator 1, a situação de maior concentração da população no âmbito urbano também pode favorecer o resultado primário local do RGPS, uma vez que a clientela rural pode possuir condições diferenciadas em relação à previdência social. O contribuinte urbano tem o desconto previdenciário na folha de pagamentos todos os meses, enquanto o segurado especial pode ocorrer apenas em situação de comercialização de produtos, ainda, os contribuintes rurais conseguem o benefício de aposentadoria com menor idade (NERY, 2015; RESENDE, 2001).

A questão demográfica também foi analisada neste estudo. Na visão de Matias-Pereira (2010) e
Silva, Costa e Dias (2014), a evolução demográfica afeta o equilíbrio financeiro da previdência social principalmente diante do sistema de repartição simples que vigora no Brasil, ainda, é vislumbrava uma tendência de envelhecimento da população a médio e longo prazo. Observa-se que a variável taxa de envelhecimento apresentou correlação negativa no fator 2 e na análise por categorias, evidenciando maior dificuldade para o RGPS em municípios com população mais idosa. Avaliando as questões trabalhistas, também componente do fator 2 , verificou-se a importância da manutenção de um elevado nível de emprego formal para o equilíbrio financeiro da previdência social, pois na visão de Silva, Costa, Dias (2014) e Rocha, Macário (2015) a previdência social é financiada com maior ênfase pela população economicamente ativa com ocupação de carteira assinada. As variáveis taxa de atividade e percentual de recursos provenientes do trabalho corroboram para o entendimento da influência das questões trabalhistas no resultado previdenciário primário por municípios.

O fator 3, escolaridade, também demonstrou influência quando relacionado às características municipais sobre os resultados do RGPS, conforme o teste do qui-quadrado e AED por categoria. Considerando que esse fator envolve as variáveis IDHM Educação e expectativa de anos de estudo, observou-se que o grau de escolaridade pode contribuir para maiores salários e consequentemente maiores recursos investidos na previdência social (BALASSIANO; SEABRA; LEMOS, 2005).

\section{CONSIDERAÇÕES FINAIS}

Avaliando a influência de fatores externos no resultado primário previdenciário no RGPS, percebeu-se que o desenvolvimento socioeconômico foi o principal fator influente no cenário financeiro da previdência social por município. Outros fatores de destaque, com menor grau de influência, também foram ser destacados, a exemplo da distribuição populacional, dos aspectos demográficas, das características trabalhistas e de escolaridade.

Embora a literatura sobre o assunto ressalte a importância dos recursos dispendidos pela previdência social para manutenção econômica de municípios, 
com mais relevância os de pequeno porte, este estudo apresenta a relação inversa, indicando a influência da situação socioeconômica do município no equilíbrio financeiro da previdência social no escopo local, enquanto melhor a situação de desenvolvimento socioeconômico do município mais equilibrada é a situação financeira do RGPS naquela localidade. Também se ressalta a relação direta entre o cenário trabalhista e a estabilidade financeiro da previdência social, assim como a relação inversa entre a evolução demográfica e a austeridade da previdência social.

Diante do exposto, ao se confirmar a hipótese levantada, existindo uma estreita relação entre as condições socioeconômicas locais e o equilíbrio financeiro do RGPS, tem-se uma relevante contribuição para literatura. Pode se entender que as condições financeiras previdenciárias, além dos aspectos demográficos, são influenciadas pelo mercado de trabalho, por o desenvolvimento humano e pela condição econômica, portanto, é um reflexo do contexto local. No estado de Minas Gerais a ampla desigualdade socioeconômica entre as regiões e os municípios é retratada pelas discrepância nas contas municipais do RGPS.É interessante evidenciar que este estudo trabalhou com os montantes exclusivos da previdência social, não utilizando nas análises as receitas das contribuições sociais, como a CSLL e o Cofins, que podem, de acordo a visão constitucional, se integrar às receitas da previdência social. Essa escolha foi feita diante da preocupação em explicar características que podem influenciar nas arrecadações e nos benefícios previdenciários em um âmbito atuarial, sem a pretensão de entrar na seara da discussão sobre a existência do déficit previdenciário. Porém, enfatiza-se que ao se indicar a relação entre as condições socioeconômicas e o equilíbrio previdenciário não se exclui a possibilidade de má gestão, fraudes e outros fatores, como o próprio desenvolvimento demográfico, afetarem em menor amplitude o equilíbrio previdenciário.

Ressalta-se que a principal dificuldade encontrada para este estudo foi a falta de dados atualizados e a indisponibilidade dos montantes arrecadados e dispendidos para todos os municípios de Minas Gerais. Com esta pesquisa, abre-se espaço para novas propostas, uma vez que seria importante avaliar o peso desses fatores na explicação dos resultados do RPGS, complementando os resultados, que eviden- ciou a existência de relação de dependência entre os fatores encontrados e os resultados previdenciários do RGPS nos municípios de Minas Gerais.

\section{REFERÊNCIAS:}

AFONSO, L. E. Progressividade e Aspectos Distributivos na Previdência Social: Uma Análise com o Emprego dos Microdados dos Registros Administrativos do RGPS. Revista Brasileira de Economia. Rio de Janeiro v.70n.1/p.3-30 Jan-Mar, 2016.

ALMEIDA-FILHO, N. de; PAIM, J. S.; VIEIRA-DASILVA, L. M. Saúde Coletiva: futuros possíveis. In: In: Paim JS, Almeida-Filho N, organizadores. Saúde coletiva: teoria e prática. 1a ed. Rio de Janeiro: Medbook; 2014.

ATLAS DO DESENVOLVIMENTO HUMANO NO BRASIL. Consulta. 2013. Disponível em: < http:// atlasbrasil.org.br/2013/pt/consulta/ > . Acesso em: 10 nov. 2016.

\section{ATLAS DO DESENVOLVIMENTO HUMANO}

NO BRASIL. Glossário. Disponível em: < http:// www.atlasbrasil.org.br/2013/pt/o_atlas/glossario/ >. Acesso em: 11 nov. 2016.

BALASSIANO, M.; SEABRA, A. A de.; LEMOS, A. H. Escolaridade, Salários e Empregabilidade: Tem Razão a Teoria do Capital Humano?. RAC, v. 9, n. 4, Out./Dez. 2005.

BARR, N.; DIAMOND, P. Pension reform: A short guide. New York: Oxford University Press, 2010.

BATANERO C.; ESTEPA A.; GODINO J.D. Análisis exploratorio de datos: sus posibilidades en la enseñanza secundaria. Suma, 9, 25-31. 1991.

BITENCOURT, B. M.; GALLON, S; BATISTA, K. M.; PICCININI, V. C. Para Além do Tempo de Emprego: o sentido do trabalho no processo de aposentadoria. Revista de Ciência da Admnistração, v.13, n 31, 2011. 
BRASIL. Constituiçãa (1988). Constituição da República Federativa do Brasil. Brasília: Senado Federal: Centro Gráfico, 1988.

BRASIL. LEI No 8.212, DE 24 DE JULHO DE 1991. Disponível em: < https://www.planalto.gov.br/ ccivil_03/leis/L8212cons.htm >. Acesso em 07 de Novembro de 2016.

BRASIL. Lei no 8.213, de 24 de julho de 1991. Dispõe sobre a organização da Seguridade Social, institui Plano de Custeio, e dá outras providências. Disponível em: <www.planalto.gov.br/ccivil_03/leis/18213cons. htm>. Acesso em: 20 mai. 2016.

BURKHAUSER, R. ET AL. Social Security research at the Michigan retirement research center. Social Security Bulletin - Vol.69 - No. 4. 2009.

BUSQUETS, J. M. Las re-reformas de los sistemas de pensiones en: Argentina, Bolivia, Chile y Uruguay. (2003-2010). Cuarto Congreso Uruguayo de Ciencia Política, "La Ciencia Política desde el Sur", Asociación Uruguaya de Ciencia Política, 14-16 de noviembre de 2012.

CIRINO, J. F.; GONZÁLEZ, A. M. G. O. A heterogeneidade do desenvolvimento econômico do estado de Minas Gerais. Revista de C. Humanas, Viçosa, v. 11, n. 1, p. 9-23, jan./jun. 2011.

CONFEDERAÇÃO NACIONAL DOS TRABALHADORES DA AGRICULTURA (CONSAG). Previdência Social Rural: Potencialidades e Desafios. Brasília, 2016.

CUNHA, A. R. G. Contabilidade Previdenciária: um estudo sobre o grau de conformidade das práticas contábeis dos Regimes Próprios de Previdência Social dos municípios pernambucanos. Dissertação de Mestrado, Recife: UFPE, 2013.

DAVI, J. et al. A Seguridade Social em tempos de crise do capital: o desmonte de seu orçamento. SER Social, Brasília, v. 12, n. 26, p. 59-87, jan./jun. 2010.
DELGADO, G. C. Previdência Social e Desenvolvimento Rural. In: GRISA, C.; SCHNEIDER, S. Políticas Públicas de Desenvolvimento Rural no Brasil. Editora UFRGS, p. 429 - 442, 2015.

Departamento Intersindical de Estatística e Estudos Socioeconômicos (DIEESE); Associação Nacional dos Auditores Fiscais da Receita Federal do Brasil (ANFIP). Previdência: reformar para excluir? Contribuição técnica ao debate sobre a reforma da previdência social brasileira - Brasília: DIEESE/ ANFIP; 2017.

ESPING-ANDERSON, GOSTA. O futuro do Welfare State na nova ordem mundial. In: Lua Nova, número 35. Princeton, Princeton university press, 1995.

ESPING-ANDERSON, G. As três economias políticas do Welfare State. In: The theree worlds of welfare capitalism. Princeton, Princeton university press, 1990.

FEDERAÇÃO DAS INDUSTRIAS DO ESTADO DO RIO DE JANEIRO. Índice FIRJAN de desenvolvimento municipal. Disponível em: $<$ http:// www.firjan.com.br/ifdm/ >. Acesso em: 11 nov. 2016.

FELDSTEIN, M. Structural Reformo of Social Security. Journal of Economic Perspectives - volume 19, number 2, pages 33-55. 2005.

FIGUEIREDO, D.; SILVA, J. Visão além do alcance: uma introdução à análise fatorial. OPINIÃO PÚBLICA, Campinas, vol. 16, nº 1, Junho, 2010.

GENTIL, D. L. A Política Fiscal e a Falsa Crise da Seguridade Social Brasileira - Análise financeira do período 1990-2005. Tese de Doutorado, Universidade Federal do Rio de Janeiro, 2006.

A previdência social 'paga o preço' do ajuste fiscal e da expansão do poder financeiro. Revista da ABET, v. 16, n. 1, Setembro/Outubro de 2017.

GIAMBIAGI, Fábio; ALÉM, Ana Claudia. Finanças Públicas: Teoria e Prática no Brasil. Elsevier Editora, $5^{\circ}$ edição, 2016. 
GIAMBIAGI, Fábio. Et al. Diagnóstico da previdência social no Brasil: o que foi feito e o que falta reformar? IPEA, pesquisa e planejamento econômico, v.34, n.3. 2004.

GIL, A. C. Métodos e Técnicas de Pesquisa Social. 5 ed. São Paulo: Atlas, 1999.

HAIR JR., J.; ANDERSON, R. E.; TATHAM, R. L.; BLACK, W.C. Análise Multivariada de Dados. $5^{\circ}$ Edição, Porto Alegre: Bookman, 2005.

IBRAHIM, F. Z. Curso de Direito Previdenciário. $21^{\circ}$ ed. Rio de Janeiro: Impetus, 2015.

HOBSBAWM, Eric J. Rumo ao abismo econômico. In: A era dos extremos: o breve século XX. São Paulo: Companhia das Letras, 1995.

INSTITUTO BRASILEIRO DE GEOGRAFIA E ESTATÍSTICA (IBGE). Conceitos. Disponível em: < http://www.ibge.gov.br/home/estatistica/populacao/ condicaodevida/indicadoresminimos/conceitos.shtm >. Acesso em: 11 nov. 2016.

KRITZER, B. E. Social Security Reform in Central and Eastern Europe: Variations on a Latin American Theme. Social Security Bulletin • Vol. 64 • No. 4 • 2001/2002.

MANTEL, N.; HAENSZEL, M. W. Statistical aspects of thee analysis of data from retrospective studies of disease. J Nat Cancer Inst. 1959.

\section{MATIAS-PEREIRA, José. Reforma da previdência} em discussão: expectativas e possibilidades diante da janela de oportunidades demográficas. Universidade de Brasília, 2010.

MACIEL, et al. Segmentação dos consumidores a respeito dos produtos orgânicos. Revista Capital Científico - Eletrônica (RCCe). Vol. 13 n.3 - Julho/ Setembro 2015.
MARTELLO, A. G1. Governo estima rombo de R\$ 183 bilhões na Previdência em 2017. Disponível em: < http://g1.globo.com/economia/noticia/2016/07/ governo-estima-rombo-de-r-183-bilhoes-na-previdencia-em-2017.html >. Acesso em: 15 jul. 2016.

NERY, P. F. A previdência tem déficit ou superávit? Considerações tem tempos de "CPMF da previdência". Senado Federal. Boletim legislativo n 37, de 2015.

PESTANA, M. H.; GAGEIRO, J. N. Análise de dados para ciências sociais: A complementariedade do SPSS. $5^{\circ}$ edição, Edições Sílabo, 2008.

POLIVKA, L.; LUO, B. The Neoliberal Political Economy and Erosion of Retirement Security. The Gerontologist (Oxford) v. 55, n², Oxford, 2015.

PREVIDÊNCIA SOCIAL, Estatísticas Municipais 2000 a 2015. Disponível em:< http://www.previdencia.gov.br/dados-abertos/estatsticas-municipais-2000-a-2015/ >. Acesso em: 10 set. 2016.

PREVIDÊNCIA SOCIAL, BEPS 2015. Disponível em:< http://www.previdencia.gov.br/dados-abertos/ $>$. Acesso em: 10 set. 2016.

REIS, P. R. da C.; SILVEIRA, S. de F. R.; BRAGA, M. J. Previdência social e desenvolvimento socioeconômico: impactos nos municípios de pequeno porte de Minas Gerais. Rev. Adm. Pública - Rio de Janeiro 47(3):623-646, maio/jun. 2013.

RESENDE, F. A. Finanças Públicas. $2^{\circ}$ edição - São Paulo: Atlas, 2001.

ROCHA, F. R. F.; MACÁRIO, E. Padrão atual de acumulação de capital, mundo do trabalho e reestruturação da previdência social no Brasil. R. Katál., Florianópolis, v. 18, n. 2, p. 191-201, jul./dez. 2015.

SALVADOR, E. S. O desmonte do financiamento da seguridade social em contexto de ajuste fiscal. Serv. Soc. Soc., São Paulo, n. 130, p. 426-446, set./dez. 2017. 
SASS, S. A. Will social security keep fewer of tomorrow's elderly out of poverty? Center for Retirement Research at Boston College, Number 15-19, 2015.

SERAU JÚNIOR, M. A. Economia e Seguridade Social: Análise Econômica do Direito - Seguridade Social. Curitiba: Juruá, 2012.

SILVA, L. L da.; COSTA, T. de M. T. da.; DIAS, W. B. Impacto de Variáveis Macroeconômicas nas Receitas e Despesas do Regime Geral da Previdência Social no Brasil. EnAPG, ANPAD. Belo Horizonte, 2014.

SILVA, L. L da. Et al. A previdência social brasileira como instrumento de política pública. XVIII Congreso Internacional del CLAD sobre la Reforma del Estado y de la Administración Pública, Montevideo, Uruguay, 29 oct. - 1 nov. 2013.

SUZIGAN, W.; FURTADO, J. GARCIA, R. SAMPAIO, S. A indústria de calçados de Nova Serrana (MG). Nova Economia, Belo Horizonte_15 (3)_97-116_setembro-dezembro de 2005.

TAFNER, P.; BOTELHO, C. ERBISTI, R. Debates sobre a previdência: as convergências. In: Reforma da previdência: a visita da velha senhora. Editora Gestão Pública: Brasília, 2015.

TANAKA, E. Direito Previdenciário. São Paulo: Editora Método, 2016.

YAZBEK, M.C. Políticas Sociais e Assistenciais: Estratégias Contraditórias de Gestão Estatal da Pobreza das Classes Subalternas. In: Classes subalternas e assistência social. Cortez Editora, oitava edição. 2015. 